\title{
Body Mass Index, Fatty Liver Index and Other Metabolic Disturbances Differentially Affect Albuminuria and Glomerular Filtration Rate in the General Population
}

\author{
Adrien Bigot ${ }^{1,2 *}$, Gaëlle Gusto ${ }^{3}$, Nane Copin ${ }^{3}$, Bénédicte Sautenet ${ }^{1}$, Olivier Lantieri'2,3 and Jean-Michel Halimi ${ }^{1,4}$ \\ ${ }^{1}$ Service de Néphrologie-Immunologie Clinique, Hôpital Bretonneau, CHRU Tours, Tours, France \\ ${ }^{2}$ Service de Médecine Interne, Hôpital Bretonneau, CHRU Tours, Tours, France \\ Institut inter Régional pour la Santé, Tours, France \\ ${ }^{4}$ EA 4245, Université François-Rabelais, Tours, France
}

\begin{abstract}
Objective: Obesity and diabetes mellitus increase the risk of chronic renal disease. However, whether Body Mass Index (BMI) and metabolic disturbances are associated with renal dysfunction, and affect similarly albuminuria and estimated Glomerular Filtration Rate (eGFR) are less clear. Hence, the aim of this study was to describe these associations in the general French population.
\end{abstract}

Methods: We realised a large cross-sectional study of 118,314 subjects aged $\geq 40$ years undergoing a medical examination in 11 French regional health centers.

Results: Renal dysfunction ((abnormal albuminuria ( $\geq 30 \mathrm{mg} / \mathrm{g}$ ) and/or low eGFR $\left.\left(<60 \mathrm{ml} / \mathrm{min} / 1.73 \mathrm{~m}^{2}\right)\right)$ was observed in $5.3 \%$ of subjects. There was a J-curve relationship between BMI and the risk of abnormal albuminuria: underweight (BMl<18.5 kg/m²: odds ratio: 2.12 [95\% confidence interval: 1.55-2.83]), overweight (BMI 25-29.9: 1.36 [1.24-1.50]), and obese (BMI 30-34.9: 2.66 [2.39-2.97]; BMI 35-39.9: 4.14 [3.52-4.86]; BMI>40: 7.35 [5.89-9.15]) had a greater risk of abnormal albuminuria than subjects with normal weight. In contrast, the relationship between BMI -or other metabolic disturbances- and low eGFR was continuous. Metabolic disturbances increased the risk of abnormal albuminuria to a greater extent than the risk of abnormal eGFR. High fatty liver index and high calculated risk of developing diabetes were risk factors for both abnormal albuminuria and low eGFR.

Conclusion: There is a J-curve relationship between BMI and abnormal albuminuria, in contrast to the continuous association between other metabolic disturbances and abnormal eGFR. All metabolic disturbances are associated with abnormal albuminuria, but the association with abnormal eGFR is less clear, suggesting a stronger relationship with endothelial than renal dysfunction. Abnormal albuminuria and eGFR may precede the onset of diabetes.

\section{Introduction}

The prevalence of obesity is increasing all over the world and more than doubled worldwide between 1980 and 2008 [1]. In 2010, the International Obesity Task Force estimated that 475 to 600 million adults and 40 to 50 million school-aged children were obese [2]. Obesity has consequences on cardiovascular diseases and diabetes. The consequences of obesity on cardiovascular diseases are mainly observed in subjects with metabolic syndrome. Metabolic syndrome was initially defined as the association of high blood pressure, large waist circumference, low level of High-Density Lipoprotein (HDL)cholesterol, high triglycerides level and impaired fasting glucose. Later, it appeared that other metabolic changes such as nonalcoholic steatohepatitis (NASH) or hyperuricemia could be associated with metabolic syndrome $[3,4]$. Finally, calculated scores to predict the risk of diabetes mellitus were developed with some of these parameters $[5,6]$.

Chronic Kidney Disease (CKD) is a worldwide epidemic [7]. The prevalence of CKD has increased from $10.0 \%$ to $13.1 \%$ between 1988 1994 and 1999-2004 according to the National Health and Nutrition Examination Survey (NHANES) [8]. The main causes of CKD remain diabetes and hypertension-related renal diseases, both highly influenced by obesity and metabolic disturbances $[9,10]$. Interestingly, obesity and the metabolic syndrome were found to be associated with elevated albuminuria - a marker of renal disease and endothelial dysfunctionin diabetic and non-diabetic patients $[11,12]$. However, the association of obesity and estimated glomerular filtration rate (eGFR) appeared more complicated because obesity was associated with glomerular hyperfiltration in some reports but reduced renal function in others $[10,13]$. In contrast, it was shown that underweight subjects may have a greater risk of endothelial dysfunction as compared to subjects with normal weight, but whether underweight constitutes a renal risk is unclear [14-16]. Altogether, these data suggested that weight may differentially affect albuminuria and eGFR.

Data on the effect of the other parameters indicating metabolic impairment (components of the metabolic syndrome, fatty liver status, diabetes risk scores) on albuminuria and eGFR are scarce. Whether the consequences of obesity on renal dysfunction (i.e. abnormal albuminuria and/or low eGFR) are similar to that of other components of the metabolic syndrome, fatty liver status or calculated diabetes risk score are unknown.

*Corresponding author: Adrien Bigot, Service de Médecine Interne, CHU Tours 2 Bd Tonnellé, 37044 Tours cedex, France, Tel: (+33) 247473715; Fax: (+33) 247479783; E-mail: adrien.bigot@univ-tours.fr

Received April 02, 2014; Accepted June 06, 2014; Published June 11, 2014

Citation: Bigot A, Gusto G, Copin N, Sautenet B, Lantieri O, et al. (2014) Body Mass Index, Fatty Liver Index and Other Metabolic Disturbances Differentially Affect Albuminuria and Glomerular Filtration Rate in the General Population. J Diabetes Metab 5: 387 doi:10.4172/2155-6156.1000387

Copyright: ( 92014 Bigot A, et al. This is an open-access article distributed unde the terms of the Creative Commons Attribution License, which permits unrestricted use, distribution, and reproduction in any medium, provided the original author and source are credited. 
Citation: Bigot A, Gusto G, Copin N, Sautenet B, Lantieri O, et al. (2014) Body Mass Index, Fatty Liver Index and Other Metabolic Disturbances Differentially Affect Albuminuria and Glomerular Filtration Rate in the General Population. J Diabetes Metab 5: 387 doi:10.4172/21556156.1000387

Page 2 of 7

In this present large cross-sectional study, we evaluated the association of metabolic disorders, albuminuria and eGFR in a general population.

\section{Research Design and Methods}

\section{Selection of the population}

Subjects included in the present cross sectional study underwent a medical examination in one of the 11 French health centers of the inter Regional Health Institute (Institut inter-Régional pour la Santé) (IRSA) in central western part of France from January 2006 to December $2010[17,18]$. IRSA is a non-profit organization involved in preventive medicine and health promotion that offers to subjects affiliated with the national insurance health system periodic free medical examinations.

The study was restricted to subjects 40 to 79 years old ( $\mathrm{n}=128,766$ ). We excluded subjects with missing albuminuria, serum creatinine, Systolic Blood Pressure (SBP), Diastolic Blood Pressure (DBP) or fasting blood glucose values, who had experienced fever or had practiced intense physical activity the previous day, pregnant women, and women having their period $(\mathrm{n}=10,418)$. Subjects with a personal history of renal disease were also excluded $(\mathrm{n}=34)$.

\section{Parameters}

Every subject completed a self-administered sociomedical questionnaire on their socioeconomic and family status, individual and family medical history and lifestyle behaviours $[17,18]$. Fasting blood and urine samples were collected for each subject. Medications were checked by a physician. Weight and height were measured in patients with light clothings. SBP and DBP were measured in prone subjects after at least 5 minute rest, with an automatic validated device (Omron $705 \mathrm{CP}{ }^{\circ}$ ). Physical activity was defined according to 3 questions on duration and regularity of physical activity at home, at work, and during sport.

All blood samples were collected after overnight fasting for about 12 hours. Several biochemical parameters were assessed by use of the C8000 Architect Abbott analyzer. Fasting glucose was measured by hexokinase method. Albuminuria was measured by immunoturbidimetry. HDL-cholesterol level was evaluated by a direct enzymatic method. Creatinine was measured by direct kinetic Jaffe's method $[17,18]$.

\section{Definitions}

Low-Density Lipoprotein (LDL) cholesterol level was calculated according to the Friedewald equation [19]. Diabetes mellitus was defined as fasting glucose level over $7.0 \mathrm{mmol} / \mathrm{L}$ or the use of at least one glucose lowering medication. Abnormal albuminuria was defined as an urine albumin to creatinine ratio $\geq 30 \mathrm{mg} / \mathrm{g}$. eGFR was calculated according to the abbreviated Modification of Diet in Renal Disease (MDRD) equation [20]. Low eGFR was defined as an eGFR $<60 \mathrm{~mL} /$ $\mathrm{min} / 1.73 \mathrm{~m}^{2}[21]$. Underweight was defined as a body mass index (BMI) value $<18.5 \mathrm{~kg} / \mathrm{m}^{2}$. Obesity was defined as BMI $\geq 30 \mathrm{~kg} / \mathrm{m}^{2}$. Normal BMI was defined as BMI between 18.5 and $24.9 \mathrm{~kg} / \mathrm{m}^{2}$. Waist circumference was defined as the smallest circumference between the lower ribs and the iliac crests. The Fatty Liver Index (FLI) was used to estimate the fatty liver status by the Bedogni formula in subjects drinking $<30 \mathrm{~g}$ alcohol per day for men and $20 \mathrm{~g}$ per day for women. This index varies from 0 to 100 , a score $\geq 60$ indicating risk of hepatic steatosis [22]. Hypertension was defined as a SBP value $\geq 140 \mathrm{mmHg}$ or DBP value $\geq 90 \mathrm{mmHg}$ or any $\mathrm{BP}$ value in subjects receiving antihypertensive medications. A diabetes risk score was calculated by the Data from the
Epidemiological Study on the Insulin Resistance Syndrome (DESIR) score, in nondiabetic subjects, as previously reported [6]. A clinical score of 5 indicates a 9 -year diabetes risk of $>30 \%$ [6]. The metabolic syndrome was defined according to NCEP ATP III definition (i.e. the presence of at least 3 of the following: HDL-cholesterol $<1.04 \mathrm{mmol} / \mathrm{L}$ for men or $1.29 \mathrm{mmol} / \mathrm{L}$ for women, fasting glucose $\geq 6.1 \mathrm{mmol} / \mathrm{L}$ or glucose lowering medication, triglycerides level $\geq 1.69 \mathrm{mmol} / \mathrm{L}$ or lipid lowering medication, $\mathrm{BP} \geq 130 / 85 \mathrm{mmHg}$ or use of antihypertensive medication, waist circumference $\geq 102 \mathrm{~cm}$ for men or $\geq 88 \mathrm{~cm}$ for women [23]). Smokers were defined as active smokers or smokers' weaned for less than 1 year.

\section{Statistical analyses}

Results are given in means \pm standard deviation or percentages, except for triglycerides, fasting plasma glucose and cholesterol, given in median (25\% and $75 \%$ quartiles) and log-transformed for the analysis, because of skewed distribution. Comparison among groups was made with covariance analysis for continuous data and logistic regression for discrete data with adjustment for age and gender. We studied the associations of various components of metabolic factors (number of components of the metabolic syndrome, FLI, estimated risk of diabetes) and abnormal albuminuria (a marker of both endothelial and renal dysfunction) and low eGFR by logistic regression with adjustments for age and gender. As the association between BMI, abnormal albuminuria and low eGFR was different than the association of albuminuria with other components of metabolic risk, this association was then studied by logistic regression with adjustment on age, gender, and smoking status, and on age, gender, smoking status, waist circumference $(\leq$ or $>102 / 88 \mathrm{~cm}$ (men/women), blood pressure (SBP/DBP $<$ or $\geq 135 / 85)$, fasting plasma glucose $(<$ or $\geq 6.1 \mathrm{mmol} / \mathrm{L})$, HDL-C $(\geq$ or $<1.04 / 1.29$ $\mathrm{mmol} / \mathrm{L}$ (men/women)), triglycerides ( $<$ or $\geq 1.69 \mathrm{mmol} / \mathrm{L}$ ), and GGT (log transformed and standardised), to check for various confounders. Analyses were made with R version 2.13.1 (Free Software Foundation, Boston, MA, USA). Significance was defined as a $p$ value $<0.05$.

\section{Results}

\section{Characteristics of the population}

We included 118,314 subjects; 61,481 (52.0\%) were men. The mean age was $53.9 \pm 8.9$ for men and $53.7 \pm 8.6$ for women. The prevalence of diabetes was $5.5 \%$ and hypertension $44.7 \%$. The prevalence of metabolic syndrome was $17.0 \% ; 16.1 \%$ of the subjects were active smokers.

Overall, $5.3 \%$ of subjects had a renal dysfunction: isolated abnormal albuminuria $\left(\geq 30 \mathrm{mg} / \mathrm{g}\right.$ ) associated with $\mathrm{eGFR} \geq 60 \mathrm{ml} / \mathrm{min} / 1.73 \mathrm{~m}^{2}$ was found in 2,613 subjects, abnormal low eGFR $(<60 \mathrm{ml} / \mathrm{min} / 1.73 \mathrm{~m})$ was observed in 3,686 subjects (Table 1), amongst whom 237 subjects had abnormal albuminuria. Overall, abnormal albuminuria was observed in 2850 subjects.

Among subjects with eGFR $\geq 60 \mathrm{~mL} / \mathrm{min} / 1.73 \mathrm{~m}^{2}$, those with abnormal albuminuria $(\geq 30 \mathrm{mg} / \mathrm{g})$ were more frequently of male gender ( $71.3 \%$ vs $52.1 \%)$, with hypertension ( $74.7 \%$ vs $43.4 \%)$, obesity $(32.1$ vs $14.6 \%)$, metabolic syndrome ( $41.4 \%$ vs $16.1 \%)$, FLI $\geq 60(50.7 \%$ vs $22.9 \%$ ), low physical activity ( $83.3 \%$ vs $76.6 \%$ ), and a calculated diabetes risk score $>30 \%$ at 9 years $(9.5 \%$ vs $3.4 \%)$ as compared to subjects with albuminuria $<30 \mathrm{mg} / \mathrm{g}$. In addition, the prevalence of diabetes mellitus and use of lipid-lowering therapy was greater (Table 1).

As compared to subjects with normal eGFR $\left(\geq 60 \mathrm{~mL} / \mathrm{min} / 1.73 \mathrm{~m}^{2}\right)$ and normal albuminuria $(<30 \mathrm{mg} / \mathrm{g})$, those with a low eGFR $(<60 \mathrm{~mL} /$ $\left.\mathrm{min} / 1.73 \mathrm{~m}^{2}\right)$ had more frequently hypertension $(63.3 \%$ vs $43.4 \%)$, 
Citation: Bigot A, Gusto G, Copin N, Sautenet B, Lantieri O, et al. (2014) Body Mass Index, Fatty Liver Index and Other Metabolic Disturbances Differentially Affect Albuminuria and Glomerular Filtration Rate in the General Population. J Diabetes Metab 5: 387 doi:10.4172/21556156.1000387

Page 3 of 7

\begin{tabular}{|c|c|c|c|c|}
\hline \multicolumn{3}{|c|}{ eGFR=60 mL/min/1.73m } & \multirow{2}{*}{ eGFR $<60 \mathrm{~mL} / \mathrm{min} / 1.73 \mathrm{~m}^{2}$} & \multirow{2}{*}{ p value* } \\
\hline & Albuminuria $<30 \mathrm{mg} / \mathrm{g}$ & Albuminuria $\geq 30 \mathrm{mg} / \mathrm{g}$ & & \\
\hline N & 112,015 & 2,613 & 3,686 & \\
\hline Age (years) & $53.5 \pm 8.6$ & $56.7 \pm 9.5$ & $60.8 \pm 9.2$ & $<0.00001$ \\
\hline Men (\%) & 52.1 & 71.3 & 33.2 & $<0.00001$ \\
\hline Hypertension (\%) & 43.4 & 74.7 & 63.3 & $<0.00001$ \\
\hline Treated hypertension (\%) & 16.4 & 33.3 & 38.9 & $<0.00001$ \\
\hline Diabetes (\%) & 5 & 20.8 & 8.5 & $<0.00001$ \\
\hline Lipid-lowering drug (\%) & 12.5 & 22.4 & 27.4 & $<0.00001$ \\
\hline $\mathrm{BMI}\left(\mathrm{kg} / \mathrm{m}^{2}\right)$ & $25.7 \pm 4.4$ & $28.1 \pm 5.6$ & $26.8+-4.8$ & $<0.00001$ \\
\hline Obesity $^{\dagger}(\%)$ & 14.6 & 32.1 & 21.3 & $<0.00001$ \\
\hline $\mathrm{SBP}(\mathrm{mmHg})$ & $134 \pm 17$ & $148 \pm 21$ & $139 \pm 19$ & $<0.00001$ \\
\hline $\mathrm{DBP}(\mathrm{mmHg})$ & $80 \pm 10$ & $87 \pm 12$ & $81 \pm 10$ & $<0.00001$ \\
\hline Waist circumference $(\mathrm{cm})$ & $88.2 \pm 12.7$ & $96.8 \pm 14.4$ & $89.8 \pm 13.6$ & $<0.00001$ \\
\hline Total cholesterol $(\mathrm{mmol} / \mathrm{L})^{\ddagger}$ & $5.66(5.04-6.31)$ & $5.66(4.94-6.41)$ & $5.72(5.04-6.41)$ & 0.0007 \\
\hline LDL-cholesterol (mmol/L) & $3.65 \pm 0.86$ & $3.58 \pm 0.99$ & $3.66 \pm 0.90$ & $<0.00001$ \\
\hline Triglycerides & $1.05(0.79-1.46)$ & $1.35(0.96-1.95)$ & $1.14(0.84-1.57)$ & $<0.00001$ \\
\hline HDL-cholesterol (mmol/L) & $1.49 \pm 0.36$ & $1.39 \pm 0.41$ & $1.48 \pm 0.38$ & $<0.00001$ \\
\hline Fasting plasma glucose $(\mathrm{mmol} / \mathrm{L})^{\ddagger}$ & $5.11(4.77-5.49)$ & $5.44(5.00-6.22)$ & $5.11(4.77-5.55)$ & $<0.00001$ \\
\hline Serum uric acid(mg/L) & $45.27 \pm 12.83$ & $52.15 \pm 14.52$ & $50.42 \pm 14.96$ & $<0.00001$ \\
\hline Metabolic syndrome (NCEP ATP III) (\%) & 16.1 & 41.4 & 29.9 & $<0.00001$ \\
\hline Diabetes risk score $(\text { DESIR score })^{\S}$ & $2.4 \pm 1.2$ & $3.1 \pm 1.2$ & $2.8 \pm 1.2$ & $<0.00001$ \\
\hline Fatty Liver Index" & $35.6 \pm 28.1$ & $56.1 \pm 30.7$ & $44.9 \pm 29.2$ & $<0.00001$ \\
\hline Low physical activity (\%) & 76.6 & 83.3 & 80 & 0.00004 \\
\hline
\end{tabular}

Table 1: Characteristics of the population

Values are expressed as mean \pm standard deviation or percentages.

${ }^{*}$ Comparison between the three groups were made by covariance analysis for continuous data or logistic regression for discrete data with adjustments on age and gender. †Obesity: $\mathrm{BMI} \geq 30 \mathrm{~kg} / \mathrm{m}^{2}$

†Median (25\% - $75 \%$ quartiles)

\$Diabetic subjects excluded [6]

IISubjects with excessive alcohol consumption excluded [22]

eGFR: estimated Glomerular Filtration Rate; BMI: Body Mass Index; SBP: Systolic Blood Pressure; DBP: Diastolic Blood Pressure; LDL: Low-Density Lipoprotein; HDL: High-Density Lipoprotein, DESIR : Data From The Epidemiological Study On The Insulin Resistance Syndrome.

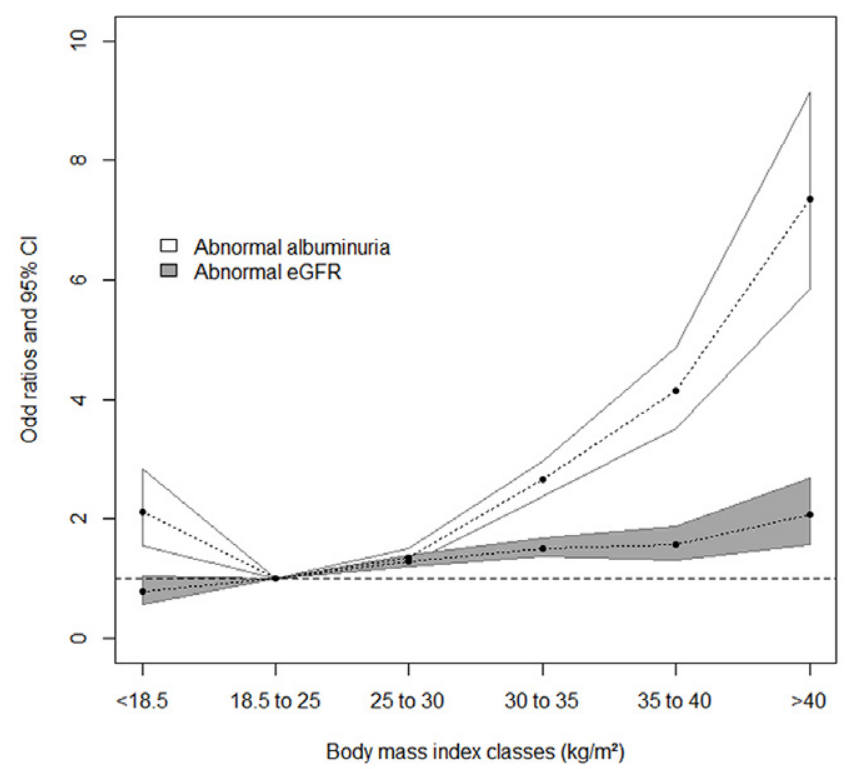

Figure 1: Renal risk by body mass index.

Age and gender adjusted odd-ratios and 95\% confidence intervals (CI). eGFR estimated glomerular filtration rate. obesity $(21.3 \%$ vs $14.6 \%)$, metabolic syndrome $(29.9 \%$ vs $16.1 \%)$, FLI $\geq 60$ (33.1\% vs $22.9 \%)$, low physical activity ( $80.0 \%$ vs $76.6 \%)$, a calculated diabetes risk score $>30 \%$ at 9 years (5.6 vs 3.4\%); however, the proportion of males was lower (33.2\% vs $52.1 \%)$ (Table 1$)$.

\section{BMI: association with risk of abnormal albuminuria and low eGFR}

There was a J-curve relationship between BMI and the prevalence of abnormal albuminuria ( $\geq 30 \mathrm{mg} / \mathrm{g}$ ) after adjustment for age and gender (Figure 1). As compared to subjects with normal BMI (18.5 to $24.9 \mathrm{~kg} /$ $\mathrm{m}^{2}$ ), underweight subjects had a greater risk of abnormal albuminuria (Odds-Ratio (OR): 2.12 [1.55-2.83], $\mathrm{p}=0.0003)$. Interestingly, underweight subjects had significantly less hypertension (22.2 vs $32.2 \%, \mathrm{p}<0.00001)$, lower LDL cholesterol levels ( $3.33 \pm 0.83$ vs $3.61 \pm$ $0.84 \mathrm{mmol} / \mathrm{L}, \mathrm{p}<0.00001)$, waist-to-hip ratio $(0.79 \pm 0.07$ vs $0.85 \pm 0.08$ , $\mathrm{p}<0.00001)$ and higher HDL-cholesterol levels $(1.78 \pm 0.41$ vs $1.60 \pm$ $0.37 \mathrm{mmol} / \mathrm{L}, \mathrm{p}<0.00001)$ than subjects with normal BMI but they were more frequently smokers ( $31.3 \%$ vs $19.8 \%, \mathrm{p}<0.00001)$. Among subjects with BMI $\geq 25 \mathrm{~kg} / \mathrm{m}^{2}$, there was a continuous relationship between BMI and abnormal albuminuria: as compared to subjects with normal BMI $\left(18.5-24.9 \mathrm{~kg} / \mathrm{m}^{2}\right)$, for subjects with BMI 25-29.9, 30-34.9, 35-39.9 and $\geq 40 \mathrm{~kg} / \mathrm{m}^{2}$, the risk of abnormal albuminuria increased with increasing BMI: OR: 1.36 [1.24-1.50], 2.66 [2.39-2.97], 4.14 [3.52-4.86] and 7.37 [5.84-9.15], respectively. 
Citation: Bigot A, Gusto G, Copin N, Sautenet B, Lantieri O, et al. (2014) Body Mass Index, Fatty Liver Index and Other Metabolic Disturbances Differentially Affect Albuminuria and Glomerular Filtration Rate in the General Population. J Diabetes Metab 5: 387 doi:10.4172/21556156.1000387

Page 4 of 7

\begin{tabular}{|c|c|c|c|c|c|c|}
\hline & \multicolumn{6}{|c|}{ BMI $\left(\mathrm{kg} / \mathrm{m}^{2}\right)$} \\
\hline & {$[18.5-25[$ (ref) } & $<18.5$ & [25-30[ & {$[30-35[$} & {$[35-40[$} & $\geq 40$ \\
\hline Albuminuria $\geq 30 \mathrm{mg} / \mathrm{g}$ & 1 & $2.12(1.55-2.83)$ & $1.36(1.24-1.50)$ & $2.66(2.39-2.97)$ & $4.14(3.52-4.86)$ & $7.35(5.84-9.15)$ \\
\hline eGFR $<60 \mathrm{ml} / \mathrm{min} / 1.73 \mathrm{~m}^{2}$ & 1 & $0.79(0.57-1.06)$ & $1.30(1.20-1.40)$ & $1.52(1.37-1.68)$ & $1.57(1.31-1.87)$ & $2.07(1.57-2.68)$ \\
\hline
\end{tabular}

Table 2: Association of Body Mass Index (BMI) and risk of renal dysfunction

Age- and gender-adjusted odds ratios and 95\% confidence intervals, eGFR: estimated Glomerular Filtration Rate

\begin{tabular}{|l|c|c|c|c|c|c|}
\hline & \multicolumn{4}{|c|}{ Number of components of the metabolic syndrome (NCEP ATP III definition) } \\
\hline & 0 (ref) & 1 & 2 & 3 & 4 \\
\hline Albuminuria $\geq 30 \mathrm{mg} / \mathrm{g}$ & 1 & $2.05(1.74-2.44)$ & $3.29(2.78-3.92)$ & $5.32(4.47-6.36)$ & $9.89(8.24-11.91)$ & $15.14(12.01-19.06)$ \\
\hline eGFR $<60 \mathrm{ml} / \mathrm{min} / 1.73 m^{2}$ & 1 & $1.13(1.01-1.26)$ & $1.54(1.37-1.73)$ & $1.89(1.66-2.14)$ & $2.16(1.86-2.51)$ & $2.56(2.01-3.22)$ \\
\hline
\end{tabular}

Table 3: Association of the number of components of metabolic syndrome and risk of renal dysfunction

Age- and gender-adjusted odds ratios and 95\% confidence intervals, eGFR: estimated Glomerular Filtration Rate

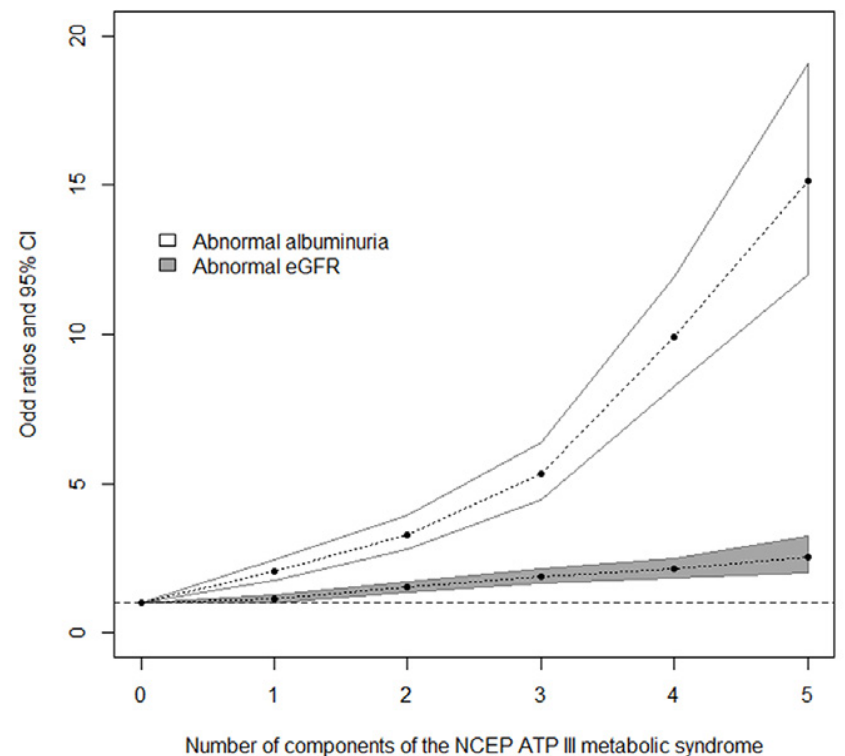

Figure 2: Renal risk by the number of components of the metabolic syndrome. NECP ATP III definition was used.

Age and gender adjusted odd-ratios and 95\% confidence intervals (CI). eGFR estimated glomerular filtration rate.

In marked contrast, the relationship between BMI and low eGFR was continuous among all BMI classes (including underweight): as compared to normal BMI, the risk of low eGFR in subjects with BMI $<18.5,25$ to $29.9,30$ to $34.9,35$ to 39.9 and $\geq 40 \mathrm{~kg} / \mathrm{m}^{2}$ was: OR: 0.79 [0.57-1.06], 1.30 [1.20-1.40], 1.52 [1.37-1.68], 1.57 [1.31-1.87] and 2.07 [1.57-2.68], respectively (Table 2).

After adjustment on age, gender and smoking status, results remained significant: as compared to normal BMI, the risk of abnormal albuminuria in subjects with BMI $<18.5,25$ to $29.9,30$ to $34.9,35$ to 39.9 and $\geq 40 \mathrm{~kg} / \mathrm{m}^{2}$ was: OR 1.49 [1.01-2.11], 1.41 [1.28-1.57], 2.82 [2.50-3.17], 4.16 [3.46-4.97] and 7.25 [5.59-9.28], respectively, and the risk of low eGFR was: OR: 0.79 [0.56-1.09], 1.28 [1.18-1.39], 1.51 [1.35$1.68], 1.62$ [1.34-1.96], 2.10 [1.56-2.78], respectively.

After adjustment on multiple confounders (age, gender, smoking status, waist, blood pressure, fasting plasma glucose, HDL-C, triglycerides, and GGT), the association remained significant: as compared to normal BMI, the risk of abnormal albuminuria in subjects with $\mathrm{BMI}<18.5,25$ to $29.9,30$ to $34.9,35$ to 39.9 and $\geq 40 \mathrm{~kg} / \mathrm{m}^{2}$ was OR: 1.51 [1.01-2.19], 1.01 [0.90-1.13], 1.30 [1.10-1.53], 1.57 [1.25-1.97], and 2.49 [1.84-3.33], respectively, and the risk of low eGFR was: OR: 0.84 [0.59-1.16], 1.22 [1.12-1.34], 1.33 [1.15-1.54], 1.41 [1.12-1.76], and $1.76[1.26-2.40]$, respectively.

\section{Metabolic syndrome: association with risk of abnormal albuminuria and low eGFR}

There was a continuous relationship between the number of components of the metabolic syndrome and the risk of abnormal albuminuria and the risk of low eGFR after adjustment on age and sex (Figure 2). However, the risk of abnormal albuminuria was greater than the risk of low eGFR, for each number of components of the metabolic syndrome. Indeed, as compared to subjects with no component of the metabolic syndrome, subjects with 1,2,3,4 or 5 components of the metabolic syndrome showed greater risk of abnormal albuminuria and low eGFR (Table 3), with the greatest risk observed in subjects with the 5 components of metabolic syndrome, (OR: 15.14 [12.01-19.06] and 2.56 [2.01-3.22], respectively).

\section{FLI: association with risk of abnormal albuminuria and low eGFR}

FLI could be estimated for 46,092 subjects. The association between the risk of elevated FLI and the risk of renal abnormalities was continuous (Figure 3). As compared to subjects with $\mathrm{FLI}<30$, those with a FLI $\geq 60$ had the greater risk of abnormal albuminuria (OR: 3.56 [3.03-4.20]) and low eGFR (OR: 1.88 [1.59-2.23]); subjects with a FLI between 30 and 60 had intermediate risk (OR: 1.48 [1.22-1.79] and 1.47 [1.24-1.75], respectively) (Figure 3).

\section{Risk of diabetes: association with risk of abnormal albuminuria and low eGFR}

For this analysis, relevant data were available for 88,223 non diabetic subjects. There was a continuous association between the calculated 9-year risk of diabetes and the risk of prevalent renal abnormalities; however the risk was especially significant for abnormal albuminuria and to a lesser degree for low eGFR (Figure 4).

As compared with subjects with a null DESIR score for incident diabetes, subjects with a score of 3,4 , or 5 showed an increased risk of abnormal albuminuria (OR: 2.25 [1.64-3.18], 3.95 [2.88-5.57] and 6.11 [4.33-8.83], respectively) and low eGFR (OR: 1.43 [1.13-1.83], 1.72 [1.36-2.21] and 1.60 [1.20-2.15], respectively) (Table 4, Figure 4). 
Citation: Bigot A, Gusto G, Copin N, Sautenet B, Lantieri O, et al. (2014) Body Mass Index, Fatty Liver Index and Other Metabolic Disturbances Differentially Affect Albuminuria and Glomerular Filtration Rate in the General Population. J Diabetes Metab 5: 387 doi:10.4172/21556156.1000387

Page 5 of 7

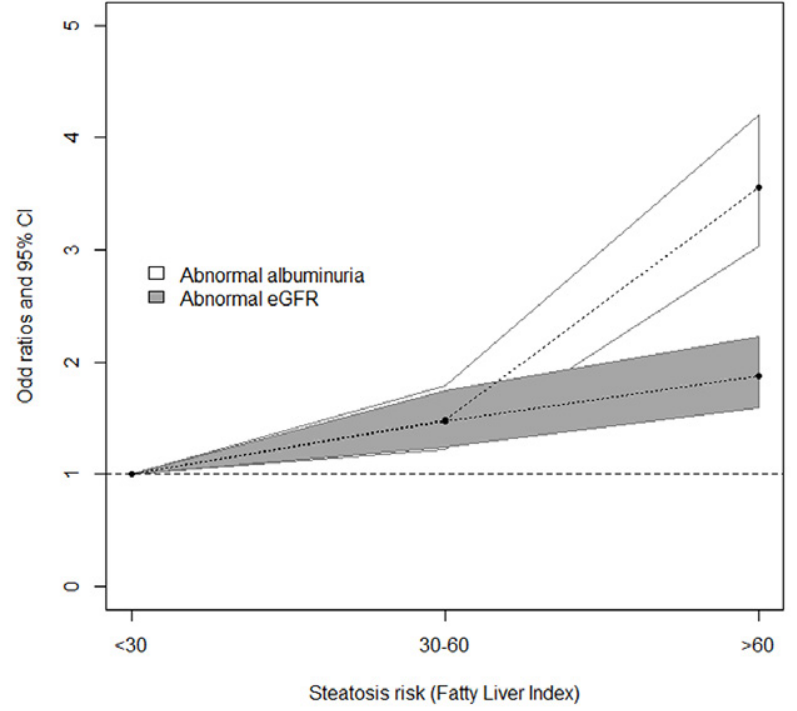

Figure 3: Renal risk by the risk of non-alcoholic steatohepatitis (NASH) $\mathrm{NASH}$ : non-alcoholic steatohepatitis; the risk of NASH was calculated using the Fatty Liver Index.

Age and gender adjusted odd-ratios and 95\% confidence intervals (CI). eGFR: estimated glomerular filtration rate.

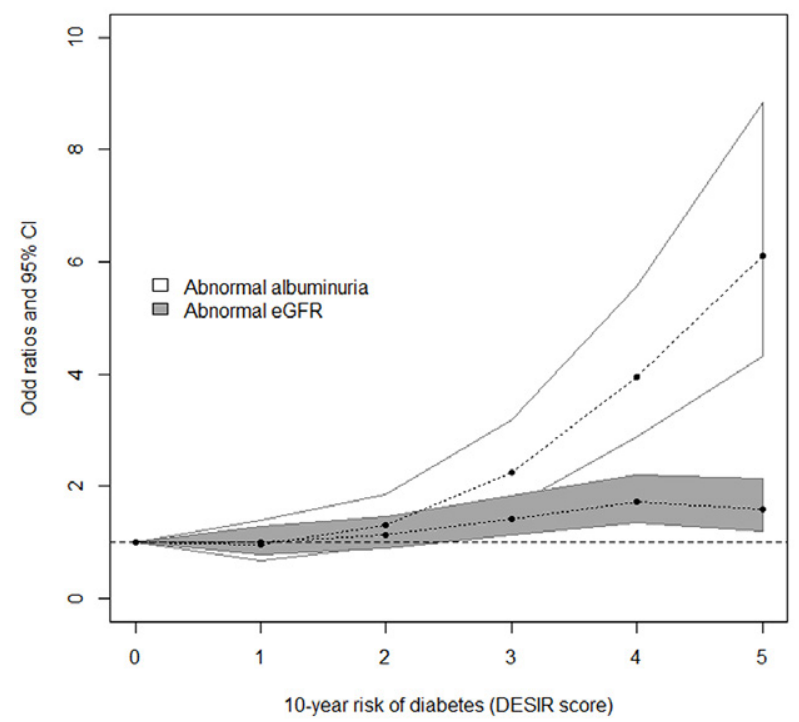

Figure 4: Renal risk by the risk of incident diabetes.

The risk of diabetes was calculated using the DESIR score.

Age and gender adjusted odd-ratios and $95 \%$ confidence intervals $(\mathrm{Cl})$. eGFR: estimated glomerular filtration rate. DESIR: Data from the Epidemiological Study on the Insulin Resistance syndrome

\section{Discussion}

In the present study, we found that $5.3 \%$ of healthy subjects from the French general population with no history of known renal disease had renal dysfunction. There was a J-curve relationship between BMI and abnormal albuminuria, but not between BMI and low eGFR. Most metabolic disturbances were strongly associated with abnormal albuminuria, but the association with low eGFR was less powerful. Risk of developing diabetes was associated with abnormal albuminuria and low eGFR in nondiabetic subjects from the general population; therefore abnormal renal function may precede the onset of diabetes.

In our large cross-sectional study of a general population, 5.3\% of subjects $\geq 40$ years had occult kidney disease. To our knowledge, this is the first estimation of the prevalence of occult kidney disease in a French adult population. In 2012, the MONA LISA study estimated the prevalence of low eGFR at $8.2 \%$ in a general population, by studying a representative sample (4,727 subjects) in another French population, but did not take into account albuminuria [24]. The prevalence of low eGFR was greater in the MONA LISA study than in our cohort, despite similar population age, proportion of subjects with hypertension or diabetes. This difference may be explained by our exclusion of subjects with a personal history of renal disease. In 2007, the prevalence of low eGFR was $13.1 \%$ in the NHANES 1999-2004 study; however, the NHANES population included up to $15 \%$ non-Caucasian subjects, whereas our population was almost exclusively Caucasian $[8,25,26]$. This lower rate of occult kidney disease is in agreement with the lower prevalence of end-stage renal disease in France (1,060 per million in 2010 [27]) than in the United States (1,752 per million [28]).

We observed a J-curve relationship between BMI and abnormal albuminuria, due to the fact that underweight subjects had a greater risk of abnormal albuminuria. Of note, underweight subjects were more frequently smokers than subjects with normal BMI in our population, and smoking constitutes a risk of abnormal albuminuria. Though, these results were scarcely modified after further adjustment on smoking status, and still reached significativity despite multiple adjustments. Interestingly, in a recent study, subjects with low BMI had a greater risk of cardiovascular disease and cardiovascular mortality as compared to subjects with normal BMI, even after adjustment for Asian populations [29]. Other explanations can be proposed: low adult weight may be explained by low birth weight, another risk factor for renal dysfunction. In healthy adults, lower weight was correlated with increased C-Reactive protein value, which suggests low-grade inflammation [14]. Unfortunately, C-Reactive protein was not measured in our population. Anorexic subjects are known to be at higher cardiovascular risk, linked with a prooxidative state and with endothelial dysfunction [30]. Whether they have also abnormal albuminuria is unknown. To the best of our knowledge, our study is the first to show increased risk of abnormal albuminuria in apparently healthy very lean subjects. Together with other results, our findings suggest that abnormal albuminuria could be a marker of endothelial

\begin{tabular}{|c|c|c|c|c|c|c|}
\hline & \multicolumn{6}{|c|}{ DESIR score } \\
\hline & 0 (ref) & 1 & 2 & 3 & 4 & 5 \\
\hline Albuminuria $\geq 30 \mathrm{mg} / \mathrm{g}$ & 1 & $0.97(0.69-1.41)$ & $1.31(0.95-1.86)$ & $2.25(1.64-3.18)$ & $3.95(2.88-5.57)$ & $6.11(4.33-8.83)$ \\
\hline eGFR $<60 \mathrm{ml} / \mathrm{min} / 1.73 \mathrm{~m}^{2}$ & 1 & $1.00(0.78-1.29)$ & $1.13(0.89-1.46)$ & $1.43(1.13-1.83)$ & $1.72(1.36-2.21)$ & $1.60(1.20-2.15)$ \\
\hline
\end{tabular}

Table 4: Association of risk of incident diabetes (DESIR score) and renal dysfunction

The score of incident diabetes was calculated using the 9-year DESIR score.

Age- and gender-adjusted odds ratios and 95\% confidence intervals,

eGFR: estimated Glomerular Filtration Rate; DESIR: Data from the Epidemiological Study on the Insulin Resistance syndrome. 
Citation: Bigot A, Gusto G, Copin N, Sautenet B, Lantieri O, et al. (2014) Body Mass Index, Fatty Liver Index and Other Metabolic Disturbances Differentially Affect Albuminuria and Glomerular Filtration Rate in the General Population. J Diabetes Metab 5: 387 doi:10.4172/21556156.1000387

Page 6 of 7

dysfunction rather than renal risk in many subjects [29]. However, this hypothesis needs to be confirmed by other studies; although many reports emphasize the importance of endothelial dysfunction as a cause of albuminuria, it remains to be proven that glomerular, podocyte or tubular dysfunction plays no role.

We found a continuous relationship between renal dysfunction (either abnormal albuminuria or low eGFR) and increased number of components of the metabolic syndrome. Metabolic syndrome is a cluster of metabolic abnormalities including abdominal adiposity, hyperglycemia, dyslipidemia, and hypertension, and several definitions have been published. In the current study, we used the NCEP ATP III definition because it is a more powerful predictor of cardiovascular disease, and as this definition is used in most of the recent studies. Metabolic syndrome is associated with low eGFR, even in nondiabetic subjects, and is associated with proteinuria, mostly in diabetic subjects [31,32]. Recently, albuminuria predicted the development of $\mathrm{CKD}$, cardiovascular disease and diabetes mellitus in subjects with metabolic syndrome [33]. In 2003, Pinto-Siesma et al. [34] showed that a central body fat distribution was associated with low eGFR, not only in obese but also lean subjects. As expected, we found metabolic syndrome associated with CKD; the relationship between the number of components of metabolic syndrome and the risk of abnormal albuminuria or low eGFR was continuous. These findings agree with other results. In 2012, Cheng et al. [31] showed that metabolic syndrome was associated with incident CKD; in 2005, Kurella et al found metabolic syndrome associated with the risk of decreased eGFR [32]. In 2004, Chen et al. [35] showed that subjects with metabolic syndrome had a greater risk of albuminuria or low eGFR in an adult U.S. population.

In the present study, there was a continuous association between renal dysfunction (abnormal albuminuria or low eGFR) and high FLI. NASH is a common cause of chronic liver disease, and its prevalence increases with obesity and diabetes. NASH is strongly linked to the clusters of metabolic syndrome [36]. In 2006, Bedogni et al developed a clinico-biological score (based on BMI, waist circumference, fasting triglycerides level, and gamma-glutamyl transferase) to predict the risk of NASH on the general population (a score $<30$ ruling out, and a score $>60$ ruling in, hepatic steatosis [22]). The presence of hepatic steatosis is associated with CKD in diabetic subjects but also in the general population [37-39]. In our study, we observed that the risk of NASH was associated with renal risk in the French population. Thus, people at risk for NASH should also be screened for CKD.

Finally, we found a continuous relationship between renal dysfunction and the calculated 9-year risk of diabetes. The practical consequences of such a finding are important: subjects with increased risk for diabetes mellitus should be considered at greater risk of CKD. Moreover, since kidney dysfunction may be present before development of diabetes mellitus, such a result indicates that renal dysfunction is not necessarily the consequence of diabetes mellitus, but that both conditions can be caused by metabolic disturbances. This result may also explain, at least in part, that GFR can decrease rapidly early during the course of diabetes mellitus as was observed in some recent reports [40]. Indeed, in the "classical" natural history of diabetes mellitus, renal function decline should occur after the development of proteinuria i.e. after a long duration of the disease, not early in the course of the disease: our observation indicate that the pathophysiology of renal function decline is more complex, and that renal function can be impaired even before the development of diabetes mellitus [39].

Admittedly, our study has some limitations: first, our population was composed of apparently healthy people with no history of renal disease. Thus, subjects with known renal disease are not represented. However, our estimation of occult renal disease is probably not overestimated. Second, this study was retrospective, and we lacked some information, such as biological markers of endothelial dysfunction. Nevertheless, it allowed us to analyze a very large healthy population, and gives reliable data on the French general population. To our knowledge, our report is the largest study on the prevalence of kidney dysfunction in a French or European - population.

In conclusion, occult kidney disease is frequent in the French general population over 40 years old. Metabolic disorders (metabolic syndrome, obesity, steatohepatitis or diabetes risk) is associated with risk of renal dysfunction. Underweight subjects are at risk for abnormal albuminuria, but is it unclear whether abnormal albuminuria represents here a marker of renal or cardiovascular risk. Finally, all subjects at risk of diabetes mellitus should also

\section{Acknowledgment}

\section{Contribution of the authors}

Adrien BIGOT wrote the manuscript, Gaelle GUSTO performed data analysis and reviewed the manuscript, Nane COPIN performed data analysis and reviewed the manuscript, Benedicte SAUTENET realised figures and reviewed the manuscript, Olivier LANTIERI researched data, contributed to the discussion and reviewed the manuscript, Jean-Michel HALIMI contributed to the discussion, wrote and reviewed the manuscript.

\section{Guarantor's name}

Jean-Michel HALIMI

\section{References}

1. WHO | Obesity [Internet]. [cited 2013 Apr 26].

2. IASO | Obesity the Global Epidemic [Internet]. [cited 2013 Apr 26]

3. Marchesini G, Bugianesi E, Forlani G, Cerrelli F, Lenzi M, et al. (2003) Nonalcoholic fatty liver, steatohepatitis, and the metabolic syndrome. Hepatology 37: 917-923.

4. Sarafidis PA, Nilsson PM (2006) The metabolic syndrome: a glance at its history. J Hypertens 24: 621-626.

5. Guasch-Ferré M, Bulló M, Costa B, Martínez-Gonzalez MÁ, Ibarrola-Jurado N et al. (2012) A risk score to predict type 2 diabetes mellitus in an elderly Spanish Mediterranean population at high cardiovascular risk. PLoS One 7: e33437.

6. Balkau B, Lange C, Fezeu L, Tichet J, de Lauzon-Guillain B, et al. (2008) Predicting diabetes: clinical, biological, and genetic approaches: data from the Epidemiological Study on the Insulin Resistance Syndrome (DESIR). Diabetes Care 31: 2056-2061.

7. Zhang QL, Rothenbacher D (2008) Prevalence of chronic kidney disease in population-based studies: systematic review. BMC Public Health 8: 117.

8. Coresh J, Selvin E, Stevens LA, Manzi J, Kusek JW, et al. (2007) Prevalence of chronic kidney disease in the United States. JAMA 298: 2038-2047.

9. Levey AS, Coresh J (2012) Chronic kidney disease. Lancet 379: 165-180.

10. Sarafidis PA (2008) Obesity, insulin resistance and kidney disease risk: insights into the relationship. Curr Opin Nephrol Hypertens 17: 450-456.

11. Locatelli F, Pozzoni P, Del Vecchio L (2006) Renal manifestations in the metabolic syndrome. J Am Soc Nephrol 17: S81-85.

12. Bonnet F, Marre M, Halimi J-M, Stengel B, Lange C, et al. (2006) Wais circumference and the metabolic syndrome predict the development of elevated albuminuria in non-diabetic subjects: the DESIR Study. J Hypertens 24: $1157-1163$

13. Gerchman F, Tong J, Utzschneider KM, Zraika S, Udayasankar J, et al. (2009) Body mass index is associated with increased creatinine clearance by mechanism independent of body fat distribution. J Clin Endocrinol Metab 94: 3781-3788. 
Citation: Bigot A, Gusto G, Copin N, Sautenet B, Lantieri O, et al. (2014) Body Mass Index, Fatty Liver Index and Other Metabolic Disturbances Differentially Affect Albuminuria and Glomerular Filtration Rate in the General Population. J Diabetes Metab 5: 387 doi:10.4172/21556156.1000387

Page 7 of 7

14. Nakajima K, Yamaoka H, Morita K, Ebata M, Equchi S, et al. (2009) Elderly people with low body weight may have subtle low-grade inflammation. Obesity (Silver Spring) 17: 803-808

15. Tzoulaki I, Jarvelin MR, Hartikainen AL, Leinonen M, Pouta A, et al. (2008) Size at birth, weight gain over the life course, and low-grade inflammation in young adulthood: northern Finland 1966 Birth Cohort study. Eur Heart J 29: 1049-1056.

16. Ramirez SP, Hsu SI, McClellan W (2001) Low body weight is a risk factor for proteinuria in multiracial Southeast Asian pediatric population. Am J Kidney Dis 38: 1045-1054.

17. Halimi JM, Giraudeau B, Vol S, Cacès E, Nivet H, et al. (2000) Effects of current smoking and smoking discontinuation on renal function and proteinuria in the general population. Kidney Int 58: 1285-1292.

18. Halimi JM, Giraudeau B, Vol S, Cacès E, Nivet H, et al. (2002) The risk of hypertension in men: direct and indirect effects of chronic smoking. J Hypertens 20: $187-193$

19. Friedewald WT, Levy RI, Fredrickson DS (1972) Estimation of the concentration of low-density lipoprotein cholesterol in plasma, without use of the preparative ultracentrifuge. Clin Chem 18: 499-502.

20. Levey AS, Bosch JP, Lewis JB, Greene T, Rogers N, et al. (1999) A more accurate method to estimate glomerular filtration rate from serum creatinine: a new prediction equation. Modification of Diet in Renal Disease Study Group. Ann Intern Med 130:461-470.

21. National Kidney Foundation (2002) K/DOQI clinical practice guidelines for chronic kidney disease: evaluation, classification, and stratification. Am J Kidney Dis 39: S1-266.

22. Bedogni G1, Bellentani S, Miglioli L, Masutti F, Passalacqua M, et al. (2006) The Fatty Liver Index: a simple and accurate predictor of hepatic steatosis in the general population. BMC Gastroenterol 6: 33

23. Grundy SM, Cleeman JI, Daniels SR, Donato KA, Eckel RH, et al. (2005) Diagnosis and management of the metabolic syndrome: an American Heart Association/National Heart, Lung, and Blood Institute Scientific Statement. Circulation 112:2735-2752.

24. Bongard V, Dallongeville J, Arveiler D, Ruidavets JB, Cottel D, et al. (2012) [Assessment and characteristics of chronic renal insufficiency in France]. Ann Cardiol Angeiol (Paris) 61: 239-244

25. Grams ME, Chow EK, Segev DL, Coresh J (2013) Lifetime incidence of CKD stages 3-5 in the United States. Am J Kidney Dis 62: 245-252.

26. Derose SF1, Rutkowski MP, Crooks PW, Shi JM, Wang JQ, et al. (2013) Racia differences in estimated GFR decline, ESRD, and mortality in an integrated health system. Am J Kidney Dis 62: 236-244.

27. rapport_2010.pdf [Internet]. [cited 2013 Apr 8]
28. 2012 Atlas of End-Stage Renal Disease - v2 ch1 12.pdf [Internet]. [cited 2013 Apr 8]

29. Chen Y, Copeland WK, Vedanthan R, Grant E, Lee JE, et al. (2013) Association between body mass index and cardiovascular disease mortality in east Asians and south Asians: pooled analysis of prospective data from the Asia Cohort Consortium. BMJ 347: f5446.

30. Rodrigues Pereira N, Bandeira Moss M, Assumpção CR, Cardoso CB, Mann GE, et al. (2010) Oxidative stress, l-arginine-nitric oxide and arginase pathways in platelets from adolescents with anorexia nervosa. Blood Cells Mol Dis 44: 164-168.

31. Cheng HT, Huang JW, Chiang CK, Yen CJ, Hung KY, et al. (2012) Metabolic syndrome and insulin resistance as risk factors for development of chronic kidney disease and rapid decline in renal function in elderly. J Clin Endocrino Metab 97: 1268-1276.

32. Kurella M, Lo JC, Chertow GM (2005) Metabolic syndrome and the risk fo chronic kidney disease among nondiabetic adults. J Am Soc Nephrol 16: 21342140 .

33. van der Velde M, Bello AK, Brantsma AH, El Nahas M, Bakker SJ, et al. (2012) Do albuminuria and hs-CRP add to the International Diabetes Federation definition of the metabolic syndrome in predicting outcome? Nephrol Dia Transplant 27: 2275-2283.

34. Pinto-Sietsma SJ, Navis G, Janssen WM, de Zeeuw D, Gans RO, et al. (2003) A central body fat distribution is related to renal function impairment, even in lean subjects. Am J Kidney Dis 41: 733-741.

35. Chen J, Muntner P, Hamm LL, Jones DW, Batuman V, et al. (2004) The metabolic syndrome and chronic kidney disease in U.S. adults. Ann Intern Med 140: 167-174.

36. Targher G, Pichiri I, Zoppini G, Trombetta M, Bonora E (2012) Increased prevalence of chronic kidney disease in patients with Type 1 diabetes and nonalcoholic fatty liver. Diabet Med 29: 220-226.

37. Targher G, Kendrick J, Smits G, Chonchol M (2010) Relationship between serum gamma-glutamyltransferase and chronic kidney disease in the United States adult population. Findings from the National Health and Nutrition Examination Survey 2001-2006. Nutr Metab Cardiovasc Dis 20:583-590.

38. Targher G, Bertolini L, Rodella S, Lippi G, Zoppini G, et al. (2010) Relationship between kidney function and liver histology in subjects with nonalcoholic steatohepatitis. Clin J Am Soc Nephrol 5: 2166-2171.

39. Chang Y, Ryu S, Sung E, Woo HY, Oh E, et al. (2008) Nonalcoholic fatty liver disease predicts chronic kidney disease in nonhypertensive and nondiabetic Korean men. Metabolism 57: 569-576.

40. Halimi JM (2012) The emerging concept of chronic kidney disease without clinical proteinuria in diabetic patients. Diabetes Metab 38: 291-297. 